\title{
Pressure drop studies of Newtonian fluids in corrugated plate heat exchangers
}

\author{
B. Sreedhara Rao ${ }^{1}$, S. Varun ${ }^{2}$, MVS Murali Krishna ${ }^{3}$, R. C. Sastry ${ }^{2}$ \\ ${ }^{1}$ Department of Chemical Engineering, CBIT Hyderabad, AP, India \\ ${ }^{2}$ Department of Chemical Engineering, NIT Warangal, AP, India \\ ${ }^{3}$ Department of Mechanical Engineering, CBIT Hyderabad, AP, India
}

Email address:

rc_sastry@yahoo.co.in (R. C. Sastry)

To cite this article:

B. Sreedhara Rao, S. Varun, MVS Murali Krishna, R. C. Sastry. Pressure Drop Studies of Newtonian Fluids in Corrugated Plate Heat Exchangers. International Journal of Mechanical Engineering and Applications. Vol. 2, No. 3, 2014, pp. 38-42.

doi: $10.11648 /$ j.ijmea.20140203.11

\begin{abstract}
The corrugated plate heat exchangers are widely used in food industry especially for pasteurization operations. Limited research work has been carried out on sinusoidal plate heat exchangers. In the present investigation, experimental studies have been carried out in a sinusoidal corrugated plate heat exchanger with water and glycerol solutions of varying concentration as test fluids. The plate heat exchanger is fabricated with two stainless steel sheets having a thickness of 1 $\mathrm{mm}$ forming a test channel having a clearance of $5 \mathrm{~mm}$ and of length $30 \mathrm{~cm} .3$ such plate heat exchangers have been fabricated with corrugation angles of 30,40 and 50 degrees. The effect of corrugation angle has been analyzed in detail and it has been observed from the experimental results that the corrugation angle is the major parameter that affects the pressure drop and the friction factor.
\end{abstract}

Keywords: Corrugated Plate Heat Exchanger, Corrugation Angle, Pressure Drop, Newtonian Fluids and Friction Factor

\section{Introduction}

Heat exchangers find use in almost all types of industries, whether it is petroleum industry or a chemical process industry. A large number of heat exchangers have been developed so far to serve very specific requirements of different industries. The heat transfer efficiency of a heat exchanger is measured on the basis of specific surface area to volume ratio $(\beta)$, the higher the value of this ratio the better it is for heat transfer operations. On this basis heat exchangers have been classified as compact heat exchanger which has a $\beta$ value greater than $700 \mathrm{~m}^{2} / \mathrm{m}^{3}$ and non compact heat exchangers having $\beta$ value less than $700 \mathrm{~m}^{2} / \mathrm{m}^{3}$. In compact heat exchangers, a lot of research has been focused on plate heat exchangers. Plate heat exchangers are highly attractive for use because of its high heat transfer efficiency, ease of handling, highly portable nature and ease with which it can be scaled up. A large number of types of plate heat exchangers exist depending on the type of corrugation present on the plate. Some commonly used corrugations include chevron type and the sinusoidal plates that are being discussed in detail in this paper. The plate heat exchangers have been studied in detail by Mckillop et al [1].
The enhancement of heat transfer in plate heat exchangers can be attributed to highly complex flow phenomena existing in between the plates. It is totally dependent on the corrugation pattern used. These corrugations introduce highly turbulent flow regime even at low Reynolds number.

Nema et al [2] have carried out similar work involving the heat transfer and pressure drop studies on a sinusoidal plate heat exchanger having a three channel arrangement. It involved study for air-water -system in the Reynolds number range 750-3200 for water and 16900-68000 for air. Bassiuony et al [3] studied different plate configurations for PHE and tried to establish a general understanding of the its effects on flow phenomena. G. Iulian et al [4] conducted exhaustive experimental studies on a chevron type plate heat exchanger, which involved the determination of nusselt number $(\mathrm{Nu})$, friction factor (f) for various flow conditions. They concluded that the flow was essentially non uniform and moved along the edges. Heggs et al [5] suggested that a pure laminar flow does not exist in a Reynolds number range of 150-11500 and supported it by studying the heat transfer coefficients experimentally. Liombas et al [6] studied the gas-liquid two phase flow in a 
wide range of Reynolds number and they concluded from the experiments that flow exhibits basics of turbulent flow for a very low value of Reynolds number like 400. Extensive mass transfer coefficients measurements were done by Goldstein et al [7] for a Reynolds number range of 150-2000. Lin et al [8] also investigated heat transfer between air-water system in a one side corrugated and one side flat system. It is observed that ample amount of literature exists for chevron type plate heat exchangers, but for sinusoidal plate heat exchangers very little work is currently available.

\section{Experimental Method}

\subsection{Experimental Setup}

The experiments have been conducted on a custom manufactured plate heat exchanger unit shown in Fig 1. The setup consists of a test box, test fluid tank, test fluid collection tank and hot water tank. Each test box consists of three sinusoidal corrugated plates welded together to form a horizontal channel. The sinusoidal plate heat exchanger shown in Fig -2 has the dimensions shown in Table-1, three test boxes of having three different corrugation angles of 30 , 40 and 50 are considered here. A manometer has been fitted across the test length to measure the pressure drop in the lower test fluid channel. The flow through these two channels is controlled using rotameters. The flow pattern adopted is countercurrent manner.

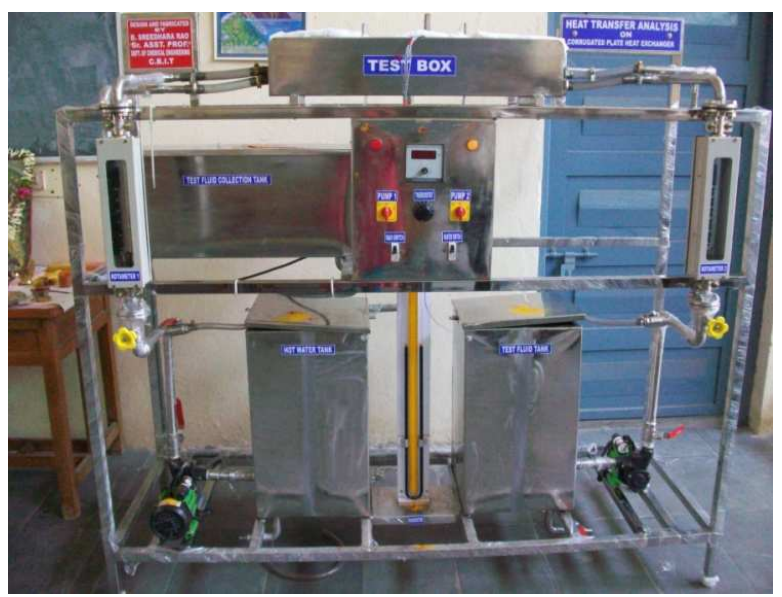

Fig 1. Plate heat exchanger setup.

Table 1. Dimensions of the plate heat exchanger test box.

\begin{tabular}{cc}
\hline Parameter & Dimensions \\
\hline Length & $0.30 \mathrm{~m}$ \\
Width & $0.1 \mathrm{~m}$ \\
Test fluid channel spacing & $0.05 \mathrm{~m}$ \\
Corrugation angles & 30,40 and 50 degrees \\
\hline
\end{tabular}

\subsection{Materials}

The test fluid considered here is water, $10 \%$ glycerol solution, $20 \%$ glycerol solution and $30 \%$ glycerol solution. $\mathrm{CCl}_{4}$ is used as the manometric fluid. The density and viscosity of all the materials are experimentally determined.

Table 2. Properties of test fluids.

\begin{tabular}{ccc}
\hline Fluid & Density & viscosity \\
\hline Water & $993.96 \mathrm{~kg} / \mathrm{m}^{3}$ & $0.7284 \mathrm{cp}$ \\
$10 \%$ glycerol solution & $1022 \mathrm{~kg} / \mathrm{m}^{3}$ & $0.9844 \mathrm{cp}$ \\
$20 \%$ glycerol solution & $1051 \mathrm{~kg} / \mathrm{m}^{3}$ & $1.392 \mathrm{cp}$ \\
$30 \%$ glycerol solution & $1080 \mathrm{~kg} / \mathrm{m}^{3}$ & $2.03 \mathrm{cp}$ \\
\hline
\end{tabular}

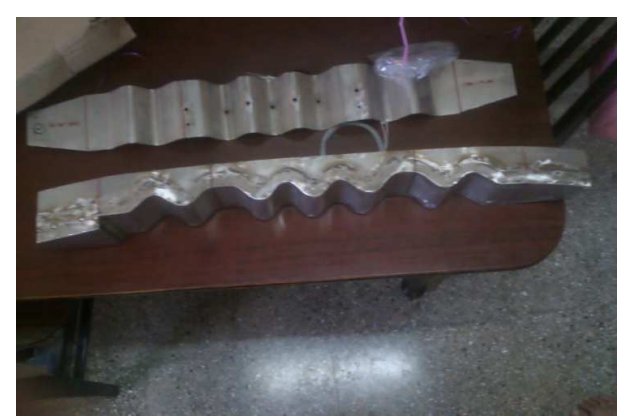

Fig 2. Sinusoidal test section.

\subsection{Experimental Procedure}

Once the test fluid is loaded in the test fluid tank, the flow is started through the channel. The flow rate is started at a lower flow rate. The test fluid flow rate is varied from 0.5 to $6 \mathrm{lpm}$ with a step size of $0.25 \mathrm{lpm}$. Once the pressure reading shown by the manometer becomes stable for a given flow rate, the pressure drop readings are noted down and process is repeated for all flow rates. The same experimental procedure is followed for all 3 test channels.

\section{Results and Discussions}

From the experimental results, it can be observed that the flow is affected by two parameters namely, the corrugation angle and the test fluid viscosity. Viscosity of the solution also affects the hydrodynamics as it also plays an important role in determining the rate of flow of test fluid through the corrugated channel. The corrugation angle forms a critical parameter in the study of plate heat exchangers. It is defined in various manners by different researchers. The corrugation angle for the plate heat exchanger is considered with respect to the horizontal as shown in Fig-3.

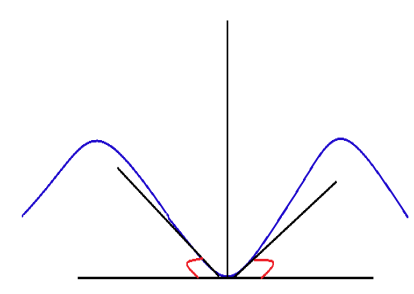

Fig 3. Corrugation angle taken for the sinusoidal plates.

It can be noted from different literature that the angle of corrugations have been defined in different manners, like Kanaris et al [9], in their study of chevron plate exchangers 
have defined angles with vertical. The corrugation angle $(\theta)$ in this study is taken with the horizontal. Abdulsayid [10] and Nema et al [2] have referred to a similar approach for considering angles In sinusoidal corrugated plate heat exchangers. If $\theta$ is taken as 0 then the plate reduces to a simple rectangular duct, and then there is no corrugation effect on the flow phenomena, when $\theta$ becomes 90 degree it results in formation of highly corrugated square channels. The turbulence effect is highest in square channels and minimum in rectangular ducts [10]. So in this study 3 cases of corrugation angles lying between 0 and 90 degrees, i.e. 30, 40 and 50 degree have been considered for analysis.

The analysis involves the calculation of the Reynolds number for the flow in test fluid channel using the equation.

The analysis involves the calculation of the Reynolds number for the flow in test fluid channel using the equation.

$$
\operatorname{Re}=\rho v D_{H} / \mu
$$

Pressure drop for each flow rate are calculated using the pressure readings obtained from the manometer.

$$
\Delta P=H \Delta \rho g
$$

Friction factor can be calculated making use of the flow velocity and the pressure drop for each flow rate.

$$
f=\Delta P /\left(\mathrm{L} / \mathrm{D}_{\mathrm{H}}\right)\left(\mathrm{G}^{*} \mathrm{G} / 2 \rho \mathrm{g}_{\mathrm{c}}\right)
$$

In detailed analysis, the variation of both $\Delta \mathrm{P}$ vs $\mathrm{Re}$ and $\mathrm{f}$ vs Re for different corrugation angles are studied.

\subsection{Pressure Drop}

For 30 degree corrugation angle, it can be observed from Fig-4 that as the Reynolds number of the flow increases, the pressure drop across the test section also increases. The increase observed is almost linear. This trend is true for all the test fluids. It can also be noted that for a given Reynolds number the more viscous fluid offers a higher pressure drop. Maximum pressure drop is offered by $30 \%$ glycerol solution and minimum by water.

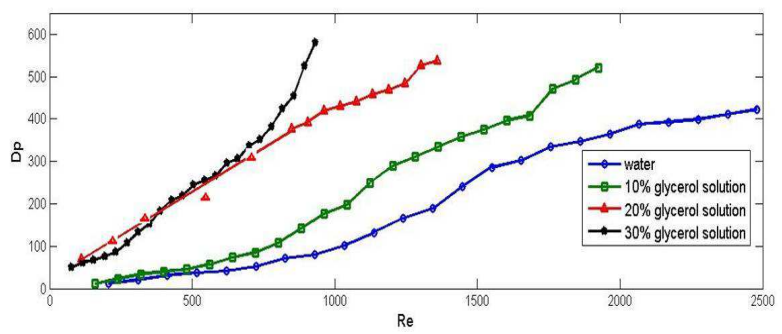

Fig 4. variation in pressure drop with Reynolds number for 30 degree corrugations

A trend similar to that of 30 degree is shown by both 40 degree (Fig-5) and 50 degree (Fig-6) corrugations. Here also the trend can be considered as almost linear.
The effect of corrugation angle can be more clearly assessed by studying the plots each test fluid separately for different corrugation angles. When all three corrugation angles are considered together (Fig-7 to Fig-10), it can be seen that the minimum pressure drop is given by the 30 degree corrugated channel and the maximum pressure is given by 50 degree corrugated test channel. This observation stands valid in the entire range of experimental study for all Reynolds number values.

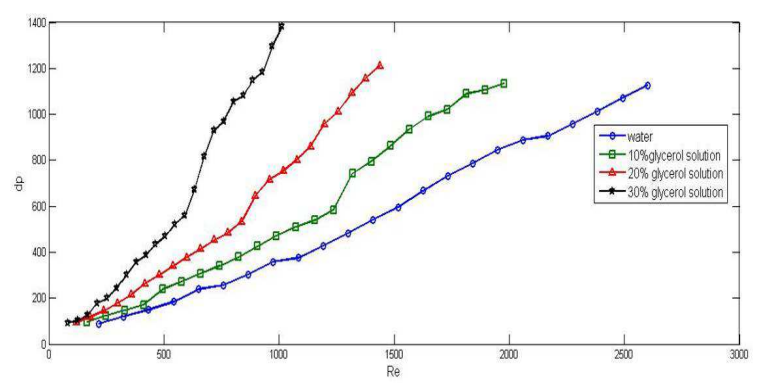

Fig 5. variation in pressure drop with Reynolds number for 40 degree corrugations

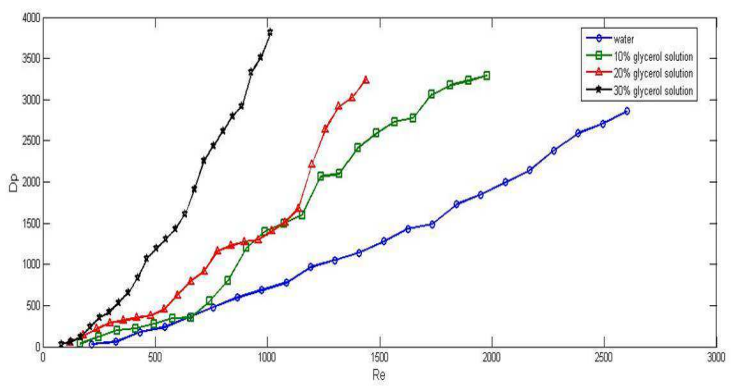

Fig 6. variation in pressure drop with Reynolds number for 50 degree corrugations

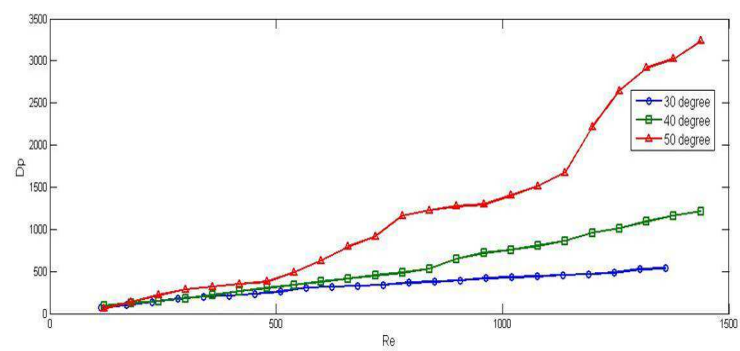

Fig 7. Comparison of pressure drop for all three corrugation angles for $20 \%$ glycerol solution.

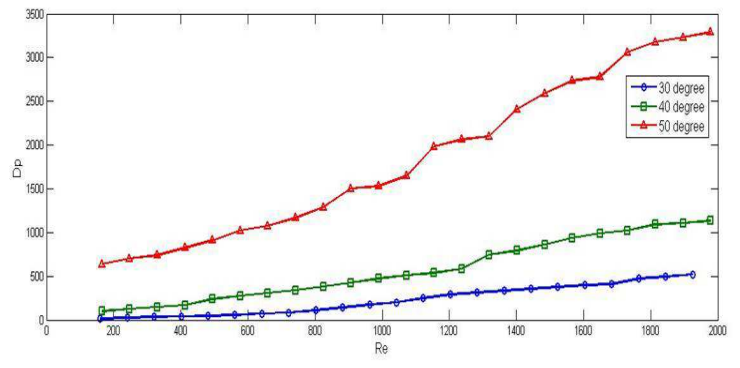

Fig 8. Comparison of pressure drop for all three corruga tion angles for $10 \%$ glycerol solution 


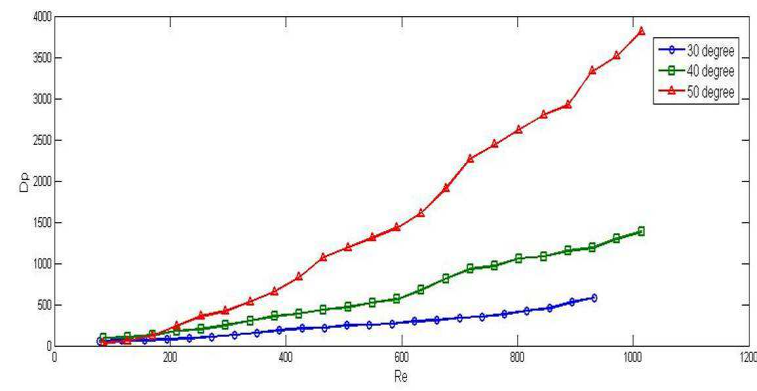

Fig 9. Comparison of pressure drop for all three corrugation angles for $30 \%$ glycerol solution.

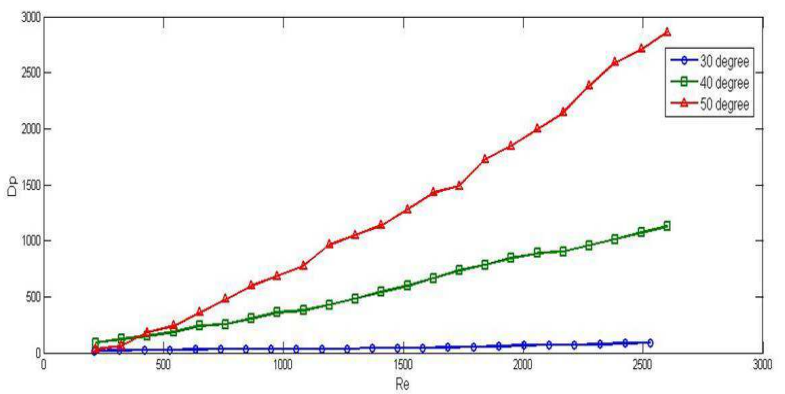

Fig 10. Comparison of pressure drop for all three corrugation angles for water.

\subsection{Friction Factor}

Theoretically as pressure drop for a flow increases, it results in decrease in the friction factor values. For 30 degree corrugation angle, it can be observed from (Fig-11) that as the Reynolds number of the flow increases, the friction factor across the test section also decreases. The decrease observed is almost linear on a logarithmic scale. For a given Reynolds number water has the highest values of friction factor and 30\% glycerol solution has minimum value of friction factor.

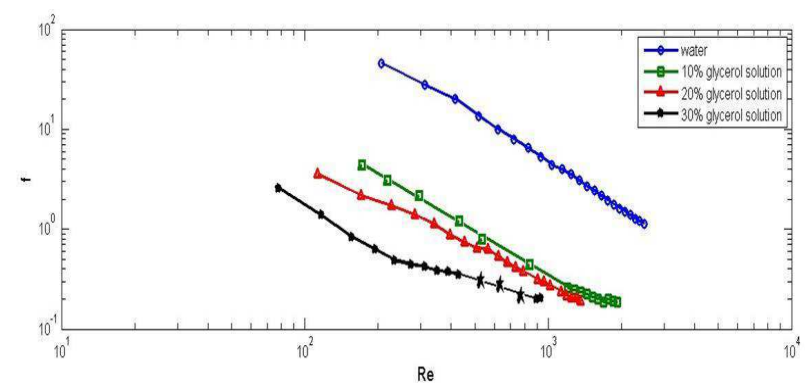

Fig 11. variation in friction factor with Reynolds number for 30 degree corrugations

For 40 degree (Fig-12) and 50 degree (Fig-13) corrugation angles, a similar trend can be observed that as the Reynolds number of the flow increases, the friction factor across the test section also decreases and the less viscous fluid always has the higher value for friction factor. But for 50 degree (Fig-13), it can be seen that due to high turbulence all the trend lines lie in vicinity of each other.

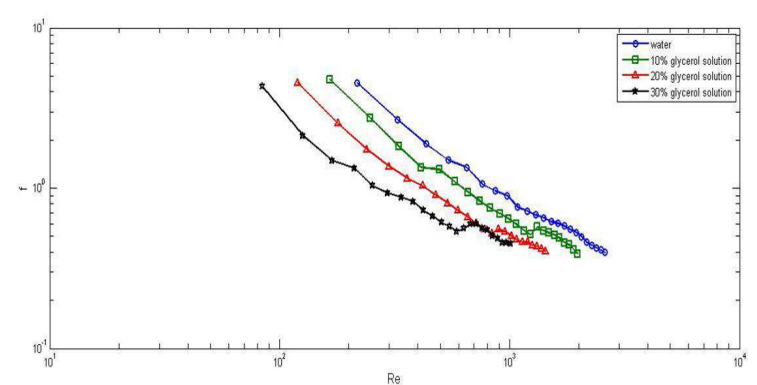

Fig 12. variation in friction factor with Reynolds number for 40 degree corrugations

When all three corrugation angle are considered together (Fig-14 to Fig-17), it can be seen that the minimum friction factor is given by the 30 degree corrugated channel and the maximum friction factor is given by 50 degree corrugated test channel. This observation stands valid in the entire range of experimental study. It can be said that as the corrugation angle increases, the pressure drop offered by the test channel increases and it results in the decrease in friction factor values.

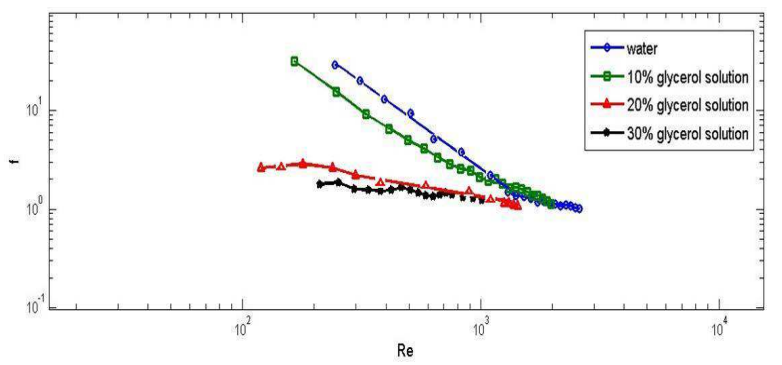

Fig 13. variation in friction factor with Reynolds number for 50 degree corrugations

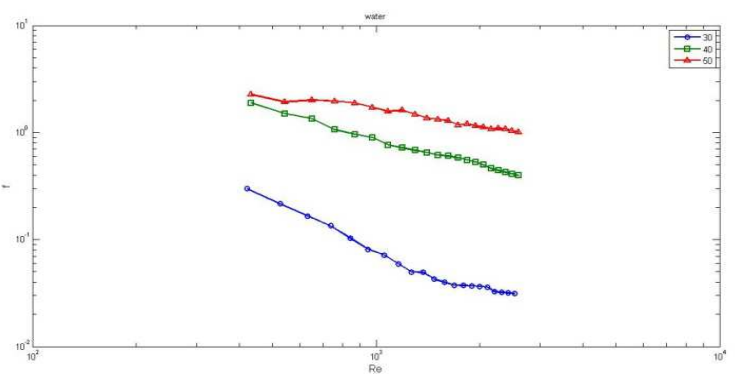

Fig 14. Comparison of friction factor for all three corrugation angles for water

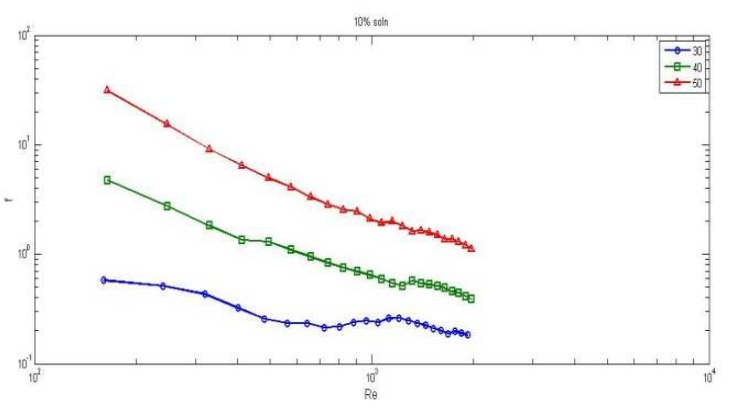

Fig 15. Comparison of friction factor for all three corrugation angles for $10 \%$ glycerol solution 


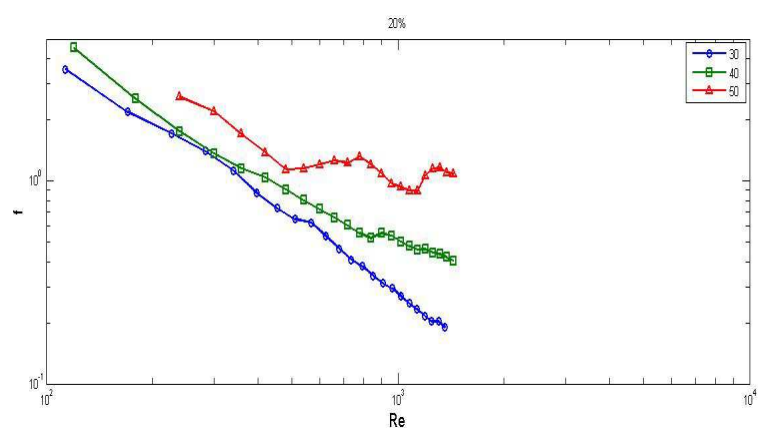

Fig 16. Comparison of friction factor for all three corrugation angles for $20 \%$ glycerol solution.

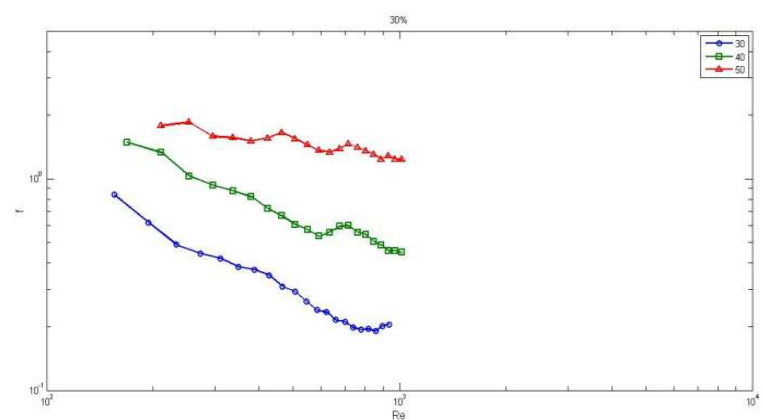

Fig 17. Comparison of friction factor for all three corrugation angles for $30 \%$ glycerol solution.

\section{Conclusions}

It is evident from the experimental analysis that both the corrugation angle and the viscosity of the test solution affect the hydrodynamics of the flow in sinusoidal corrugated channels. As the corrugation angle increases, pressure drop offered by the channel increases and the friction factor deceases. The increase in pressure drop can be attributed to increase in turbulence occurring in the channel. As the corrugation angle increases, the channel becomes sharper and induces turbulence even at a low flow rate. As the viscosity of the test fluid increases the tendency of the liquid to flow decreases or the liquid's resistance to flow increases, it results in a higher pressure drop and lower friction factor as compared to water.

\section{References}

[1] Mckillop AA, Dunkley WL. Plate heat exchangers-heat transfer. Ind Eng Chem1960;52(9):740-4.

[2] V.K. Nema, Shive Dayal Pandey,(2011), Experimental investigation of heat transfer and friction factor in a corrugated plate heat exchanger, International Journal OfEnergy And Environment, 2(2):287-296.

[3] Bassiouny MK. Flow distribution and pressure-drop in plate heat-exchangers. U-type arrangement. Chem Eng Sci 1984;39:693.

[4] Iulian Gherasim, Matthew Taws, Nicolas Galanis, Cong Tam Nguyen (2011), Heat transfer and fluid flow in a plate heat exchanger part-1: Experimental investigation, International Journal of Thermal Sciences 50:1492-1498.

[5] Heggs, P.J., Sandham, P., Hallam, R.A., Walton, C.,( 1997), Local transfer coefficients in corrugated plate heat exchangers channels, Trans IChemE, Part A, Chem Eng Res Des, 75(A7): 641-645.

[6] Lioumbas, I.S., Mouza, A.A. and Paras, S.V.,( 2002), Local velocities inside the gas phase in counter current two-phase flow in a narrow vertical channel, Trans IChemE, Part A, Chem Eng Res Des, 80(6):667-673.

[7] Goldstein. L. Jr.,Sparrow E.M. Heat mass transfercharacteristics for flow in corrugated channel: Trans: ASME Heat transfer,(1977), 99,187-195.

[8] Lin. J.H., Huang. C.Y., C.C. Su, Dimensional Analysis For The Heat Transfer Characteristics In The Corrugated Channels of Plate Heat Exchangers: International Communications in Heat and Mass Transfer, (2007), Vol. 34, pp 304-312.

[9] Athanasios g kanaris, A.A Mouza and S V Paras, Flow and heat transfer in a corrugated plate heat exchanger using a CFD code,(2006), chemical engineering technology,29,pp923-930.

[10] Abdulbasit G. A. Abdulsayid,(2012), Modeling of Fluid Flow in 2D Triangular, Sinusoidal, and Square Corrugated Channels, World Academy of Science, Engineering and Technology,71,34-52. 